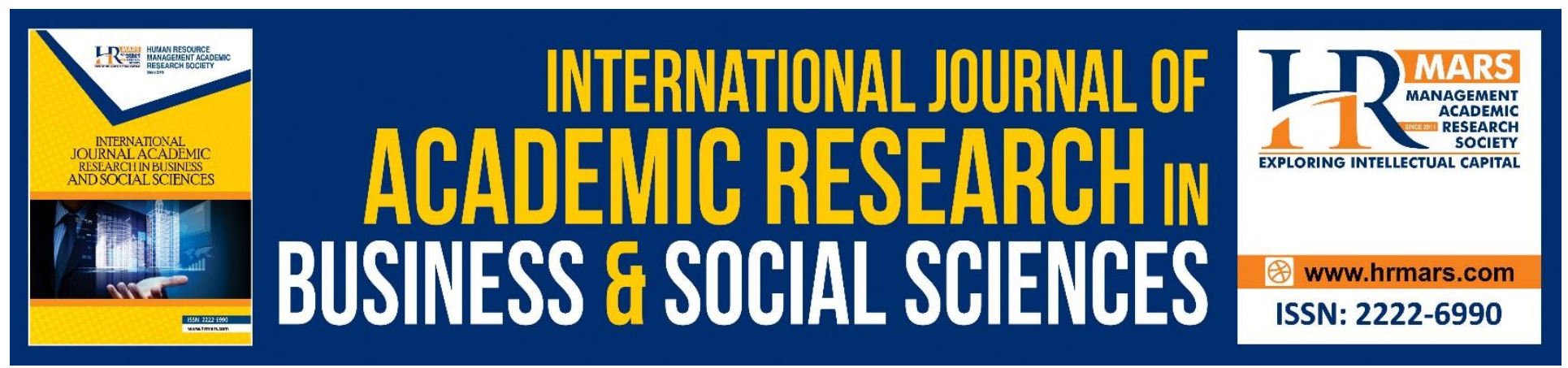

\title{
A Concept Paper on Improving Parental Knowledge and Practices on Water Safety and Their Children: A Guide for Drowning Prevention
}

Noor Hamzani Farizan, Kulanthayan K.C Mani, Rosnah Sutan \& Rozita Hod

To Link this Article: http://dx.doi.org/10.6007/IJARBSS/v11-i15/10651

DOI:10.6007/IJARBSS/v11-i15/10651

Received: 06 May 2021, Revised: 14 June 2021, Accepted: 02 July 2021

Published Online: 21 July 2021

In-Text Citation: (Farizan et al., 2021)

To Cite this Article: Farizan, N. H., Mani, K. K. ., Sutan, R., \& Hod, R. (2021). A Concept Paper on Improving Parental Knowledge and Practices on Water Safety and Their Children: A Guide for Drowning Prevention. International Journal of Academic Research in Business and Social Sciences, 11(15), 262-271.

Copyright: (C) 2021 The Author(s)

Published by Human Resource Management Academic Research Society (www.hrmars.com)

This article is published under the Creative Commons Attribution (CC BY 4.0) license. Anyone may reproduce, distribute, translate and create derivative works of this article (for both commercial and non-commercial purposes), subject to full attribution to the original publication and authors. The full terms of this license may be seen

at: http://creativecommons.org/licences/by/4.0/legalcode

Special Issue: Empowering Youth and Community Wellbeing for Sustainable Development, 2021, Pg. 262 - 271 http://hrmars.com/index.php/pages/detail/IJARBSS JOURNAL HOMEPAGE

Full Terms \& Conditions of access and use can be found at http://hrmars.com/index.php/pages/detail/publication-ethics 


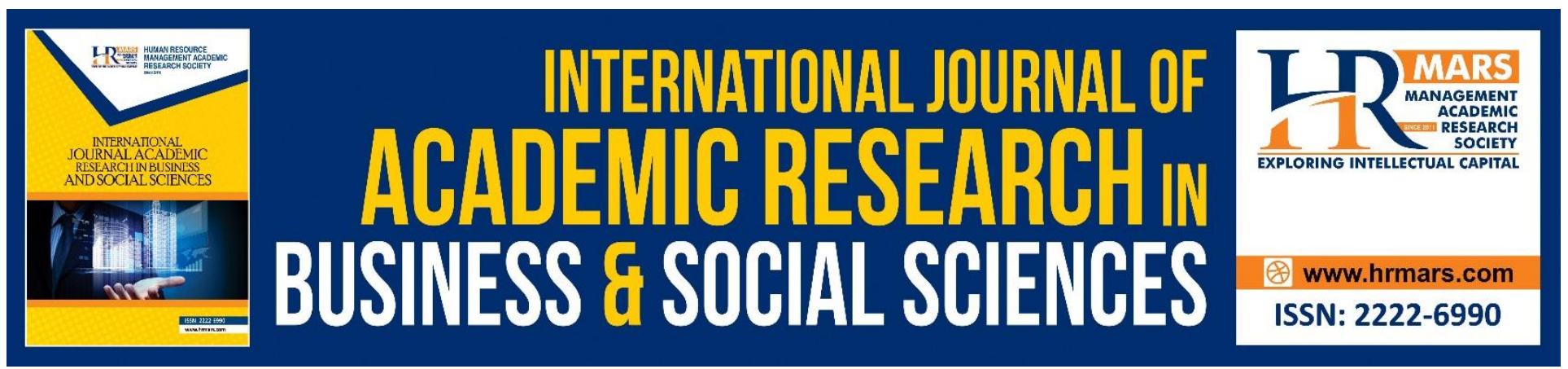

\title{
A Concept Paper on Improving Parental Knowledge and Practices on Water Safety and Their Children: A Guide for Drowning Prevention
}

\author{
Noor Hamzani Farizan², Kulanthayan K.C Mani ${ }^{1}$, Rosnah Sutan ${ }^{3}$ \& \\ Rozita Hod ${ }^{3}$ \\ ${ }^{1}$ Institute For Social Science Studies, Universiti Putra Malaysia, ${ }^{2}$ Department of Community Health, \\ Faculty of Medicine and Health Sciences, Universiti Putra Malaysia \\ ${ }^{3}$ Department of Community Health, Faculty of Medicine, Universiti Kebangsaan Malaysia \\ Email: kulan@upm.edu.my
}

\begin{abstract}
Worldwide, empirical evidence indicate that children are at heightened risk for drowning thus many substantial strategies have been made in understanding childhood drowning. Conversely, in Malaysia the data is scarce and drowning received insufficient attention. To understand the nature of the problem, the mechanism of the events and other indicators related to childhood drowning in Malaysia, a considerable research and programmatic work is required and thus appropriate intervention can be developed. As such, this conceptual paper tries to discuss the evaluation of drowning prevention awareness and practise among primary school parents and guardians. The study will collect both quantitative and qualitative data, and intends to use cross sectional survey in determining an overview of the status and current situation of water safety knowledge and preventive strategies available in this country focusing on children. The qualitative data from the study will undergo transcription and reported in theme and sub-themes discussing the assessment of attitude and practice on drowning prevention among parents and guardians of primary school children. In addition, this study aims to make an important contribution in addressing gaps in knowledge of drowning risk and prevention measured associated with children in Malaysia, prior to the development of the health educational drowning prevention guidelines for parents and guardians.
\end{abstract}

Keywords: Childhood Drowning, Drowning Prevention, Water Safety, Drowning Risk, Parents

\section{Introduction}

Drowning is a significant health problem and contributes substantially to death and morbidity. The number of victims especially children who lost their lives due to drowning was not only extremely sad, but extremely worrying. In Malaysia, Water Activity Safety Council (WASC) reported nearly 700 people drown every year, and most of the cases involve children and teenagers. In 2018, statistics of five principal causes of death by selected age group (aged 0 to 14 years) revealed accidental drowning 
and submersion rank third after transport accidents as a leading cause of deaths for children in Malaysia (Department of Statistics Malaysia, 2019). In addition, in 2019, statistics of areas with drowning cases reported 109 cases in river, 41 cases on beach, 27 cases in lake and 11 cases in waterfall (Infographic Bernama \& Fire and Rescue Department, 2019). This is in line with previous study that the most prevalent sites of drowning in Malaysia for all-age were seas and rivers (AmarSingh et al. 2014).

Drowning can occur in many different ways and the loss due to drowning is a tragedy that can be devastating to parents, siblings, family members and the surrounding community. Being parents or guardians to children, it is more important than ever to be aware of the basic principles of water safety, understanding the needs to improve knowledge and understanding of the risk and hazard around water so that in case of emergency, parents or guardians can deal with it immediately. Therefore, providing parents and guardians with knowledge to influence safer behaviours and learn skill that is necessary to protect children from drowning were hoped to be an effective intervention to aid in improving anticipatory guidance for drowning prevention.

\section{Significant of the Study}

Drowning is classified as unintentional injuries according to the means of its occurrence, thus it is predictable and preventable when proper safety precautions are taken (Peden et al. 2008). The magnitude of the drowning among children as a global public health issue is well recognized, however in this country the data is still very limited and drowning received insufficient attention. In Malaysia, the reality about drowning among children is still a major ignorance to our community. It is a neglected public health issue, perhaps because drowning is perceived as an accident and hence unpreventable.

High notified fatalities due to drowning create a tremendous public health burden in this country (Amar-Singh et al. 2014; Department of Statistics Malaysia, 2019). Furthermore, the problem has been identified for this research involves the lack of health education materials available on drowning prevention practice in a local community especially for main target groups such as parents and guardians. There is a very minimum incorporated message on drowning safety available either from local health centre or through a media campaign. Compared to other countries such as Thailand, Philippines, Australia and New Zealand, those countries deliver their water safety message, drowning awareness and campaigns through various community action channels such as media (TV, radio, newspaper and website), school programs, community programs and many more. In contrast, the only available drowning prevention information on the website of MyHEALTH, under Ministry of Health, Malaysia (PortalMyHEALTH, 2019), provides very minimum information on drowning prevention practices. Previous studies also suggested, health education material should include more clear information on drowning prevention and water safety and finding of drowning study need to be conveyed to the public to highlight the drowning issues to the general public (Amar-Singh et al. 2014).

With the limited existing drowning prevention message and water safety available locally, an assessment of parental knowledge and practice concerning childhood drowning and its preventive measures should be conducted in this country. This will assist researcher to gain a clear understanding about parents and guardian's current knowledge and practice and subsequent transfer to their children with addition in developing a set of recommendation which may be used to 
guide the development of targeted and effective drowning prevention and water safety education resources for parents and guardians.

\section{The Burden of Drowning}

The burden and death due to drowning is found in all regions. Drowning is the 3rd leading cause of unintentional injury death worldwide, accounting for $7 \%$ of all injury related deaths. Every year, over 175,000 children and youth aged 0-19 throughout the world died resulting from drowning and more than thousand suffering as a victim of non-fatal drowning events. Nearly one-half of the world's drowning occurs in Western Pacific Region and South East Asia Region and globally over $90 \%$ of drowning death accounted from low income countries and middle income countries (LMIC)(World Health Organization, 2016). In addition, several studies involving Asian countries such as Philippines, Vietnam, Indonesia and Thailand suggested that the mortality rate shows a similarity as a group and much higher compared to developed countries. On the other hand, Malaysia's average of drowning incident in children was 5.0 per 100, 000 with drowning fatality rates in 3.0 per 100, 000 children. Even though the Malaysian childhood drowning fatality rate was below the global rate as well as the Western Pacific Region LMIC rate (7.2 per 100, 000 globally, 13.9 per 100 000, Western Pacific LMIC), it was closer to the Western Pacific high-income countries (HIC) rate (1.2 per 100, 000). However, this finding was based on only a reported sources, it might be underestimated the total drowning incidents in this country and might be considered underreporting (Amar-Singh et al. 2014).

\section{Children's Vulnerability to Drowning}

Many risk factors associated with drowning among children. However, in this study, researcher will only be focused on a few factors such as age, gender, lack of supervision, swimming ability and lack of water safety awareness that was found to be related with socio-demographic and behavioural of the parents and guardians of the children.

Age

One of the major risk factors for drowning is age and quite an extensive number of studies have shown age is significant with the different patterns of drowning. Generally, children under 5 years have the highest drowning mortality rates in worldwide (Peden et al., 2008). Characteristics of drowning episodes vary greatly by age therefore different prevention strategies may be needed for different age groups. Within each age group there are different patterns of characteristics; as for an example, babies and toddler ( 0 - 4years) prone to fall into swimming pools or open water when there was no one present. An older children in 5-14 years were often become a victims of drowning when they went for swimming or boating; they fell in and incidents occurs \{Formatting Citation\}.

\section{Gender}

Large number of studies have documented that the drowning rate is significantly higher for males than in females either in adult or children (Petrass and Blitvich, 2014; Laosee et al. 2013). Malaysia shows a similar pattern regarding the gender of victims with a drowning rate ratio was 3.5 boys to 1 girl (Amar-Singh et al., 2011). Males are generally related to higher exposure to aquatic environment and disposition among males towards higher risk taking activities (Harris et al., 2006). 


\section{Lack of Supervision}

Inadequate supervision or of brief supervisor distraction were amongst the main contributor to childhood drowning. Lapse supervision were associated with parents or guardians with inconstant supervision (Yang et al., 2007) and also related to parents finding substitute of supervision, such as using other child's siblings to supervise (Callaghan et al. 2010; Morrongiello et al. 2013; Petrass et al., 2011). Other than that, higher drowning rates also associated with areas without lifeguard and the presence of a lifeguard tended to affect the chances of survival in swimming pool incidents and, to a smaller degree, in sea incidents (Tyebally \& Ang, 2010).

\section{Swimming Ability}

Generally, many studies reported evidence that swimming ability is one of the prevention strategies that may beneficial and have some protective function against drowning (Brenner, 2003). Studies in Canada reported that most of drowning victims did not know how to swim nor had a weak swimming ability (The Canadian Red Cross Society, 2003). However, there is still a debate in the literature on how swimming lesson influence children's actual drowning risk. Low or no swimming ability level has been associated with a higher risk of non-fatal drowning events. But on the other hand, swimming ability has also been associated to water-related risk behaviours (Gulliver and Begg, 2005), which may lead to a higher risk of drowning. This supports the argument that swimming lessons may increase drowning risk by fostering overconfidence in the water. (McCool et al. 2009; Moran and Willcox, 2013).

\section{Lack of water safety awareness}

Drowning incidents are attributed to the lack of water safety knowledge and unsafe behaviour around water, such as swimming unaccompanied. Toddlers who are mobile but too young to recognise a threat or who are unable to get out of water are at risk, particularly in areas where there are no protections or where competent supervision is absent. Adolescents, in addition, are less monitored and are more likely to engage in dangerous acts around water, including drinking. Studies in New Zealand suggested that the effectiveness of water safety education programs could be reinforced by increasing teenagers' ability to evaluate and managing the risk and inversely the tendency to overestimate their swimming ability and underestimate their risk with regard to drowning (McCool et al., 2008).

\section{Parental Knowledge and Practice on Children's Drowning Prevention and Water Safety}

The effectiveness of the active prevention such as providing a guidance and education on drowning prevention and basic knowledge on resuscitation and lifesaving were greatly proved affected the increasing survival of injured. The studies in New Zealand to improved parental awareness on toddler water safety was found positively successful to influence knowledge and behavioural of parents to better understand the drowning prevention and the provision of appropriate supervision and safer swimming environment for their children (Moran et al. 2012b). Distribution of knowledge and education regarding resuscitation and CPR for children also was found to be benefit to improved confidence and knowledge of parents and guardians of children and was suggested to be encouraged widely in preventing drowning among children (Moran et al., 2012a).

Conversely, studies reported in Bangladesh found there is still exits a gap between knowledge and behavioural of the parents related to drowning prevention for their children (Rahman et al. 2008). 
Even though parents who was interviewed in that studies generally have a knowledge on the causes of the drowning among children, they unable to put their knowledge into a preventive action as they failed to identified the major survival issues related to childhood drowning. This behavioural also might be related to the parents prevailing culture and belief to accept the incidents of drowning among children in inevitable, therefore there is lapse of any effort taken either at individual or community level (Rahman et al., 2008).

\section{Prevention and Intervention Strategies for Drowning Prevention}

Public health interventions include wide range of activities, aimed at reducing risk or threat to health and its normally described in three levels of categories of prevention: primary, secondary and tertiary. In the injury prevention, the primary prevention involves any attempts focused on ceasing injury events from happen, and thus relates to the time before injuries actually occur (pre-event phase). The secondary prevention includes all strategies focused at reducing the damage or harm that happen during an injury phase. The tertiary prevention comprises all efforts focused at treating and rehabilitating injured people. It is relevant with the period after an injury event has occurred (post-event phase) (Mulyono, 2010). Prevention activities also can be divided into several categories, based on the target group of interest such as in International Life Saving Federation: Drowning Prevention Strategies (ILSF). In ILSF strategies, the level of interventions of water safety were divided as universal interventions with an effort focused at large groups or the public regardless to individual risk. The selected interventions with approaches focused at those considered to be a heightened risk and individual interventions with approaches focused at those known to be of a heightened risk or at locations of known high risk (International Life Saving Federation, 2015).

Drowning can happen in many different ways; thus, it needs a range of prevention strategies to target the biggest risks. Many High Income Countries (HIC) such as the United Kingdom, United States of America, Australia and New Zealand have used several approaches such as behavioural, educational, environmental and also technological in their intervention strategies to reduce death due to drowning among children (Morrongiello et al., 2013; Moran et al., 2012b; Moran et al., 2012a). Published literature also demonstrated evidence in the effectiveness of the interventions in many countries as shows in Table 1. Efforts such as enforcement of residential pool fencing, using a media campaign and focus on education and training was found improved skills and water safety (Brenner et al. 2003; Bugeja et al. 2014; Thompson and Rivara, 2000). 
INTERNATIONAL JOURNAL OF ACADEMIC RESEARCH IN BUSINESS AND SOCIAL SCIENCES

Vol. 11, No. 15, Empowering Youth and Community Wellbeing for Sustainable Development, 2021, E-ISSN: 2222-6990 @ 2020 HRMARS

Table 1: Examples of intervention strategies for childhood drowning prevention

\begin{tabular}{|c|c|c|c|c|c|}
\hline $\begin{array}{l}\text { Level of } \\
\text { prevention }\end{array}$ & $\begin{array}{l}\text { Type of } \\
\text { Intervention }\end{array}$ & $\begin{array}{l}\text { Prevention } \\
\text { Measures }\end{array}$ & Country & Main findings & Publication \\
\hline \multirow[t]{2}{*}{ Primary } & $\begin{array}{l}\text { Developing } \\
\text { education } \\
\text { and skill }\end{array}$ & $\begin{array}{l}\text { Educate on } \\
\text { water safety }\end{array}$ & $\begin{array}{l}\text { New } \\
\text { Zealand }\end{array}$ & $\begin{array}{l}\text { Water safety } \\
\text { education improve } \\
\text { parental } \\
\text { understanding and } \\
\text { knowledge }\end{array}$ & $\begin{array}{l}\text { Moran } \\
(2008)\end{array}$ \\
\hline & $\begin{array}{l}\text { Creating } \\
\text { barrier }\end{array}$ & Pool fencing & USA & $\begin{array}{l}\text { Decreasing in } \\
\text { drowning mortality } \\
\text { rate }\end{array}$ & $\begin{array}{l}\text { Thompson } \\
\text { and Rivara } \\
(2000)\end{array}$ \\
\hline \multirow[t]{3}{*}{ Secondary } & $\begin{array}{l}\text { Managing } \\
\text { drowning }\end{array}$ & $\begin{array}{l}\text { Training in } \\
\text { CPR }\end{array}$ & USA & \begin{tabular}{l}
\multicolumn{2}{l}{ Cardiopulmonary } \\
resuscitation is \\
essential for \\
supervisor and \\
caregivers
\end{tabular} & $\begin{array}{l}\text { Engel } \\
(2015)\end{array}$ \\
\hline & $\begin{array}{l}\text { Social } \\
\text { intervention } \\
\text { and } \\
\text { education }\end{array}$ & $\begin{array}{l}\text { Supervision } \\
-\quad \text { crèche } \\
\text { and } \\
\text { swimming } \\
\text { lesson }\end{array}$ & Bangladesh & Very cost-effective & $\begin{array}{l}\text { Rahman et } \\
\text { al. (2012) }\end{array}$ \\
\hline & $\begin{array}{l}\text { Managing } \\
\text { drowning }\end{array}$ & $\begin{array}{l}\text { Training a } \\
\text { lifeguard }\end{array}$ & USA & $\begin{array}{l}\text { Lifeguard need a } \\
\text { compulsory regular } \\
\text { training } \quad \text { and } \\
\text { practice }\end{array}$ & $\begin{array}{l}\text { Schwebel et } \\
\text { al. (2007) }\end{array}$ \\
\hline Tertiary & $\begin{array}{l}\text { Legislation } \\
\text { and } \\
\text { standards }\end{array}$ & $\begin{array}{l}\text { Promotion } \\
\text { on safety } \\
\text { devices }\end{array}$ & USA & $\begin{array}{l}\text { Regulatory } \\
\text { approach to } \\
\text { personal flotation } \\
\text { device wearing to } \\
\text { reduce drowning } \\
\text { among } \\
\text { recreational } \\
\text { boaters. }\end{array}$ & $\begin{array}{l}\text { Bugeja et al. } \\
\text { (2014) }\end{array}$ \\
\hline
\end{tabular}

\section{Conclusion}

It was postulated that differences in the knowledge and the practice of childhood drowning prevention and water safety exits among parents and guardians in different socioeconomic levels in Malaysia. Moreover, the literature has discussed the burden of drowning, its related risk factors and prevention and intervention strategies for drowning prevention focusing on children and adolescents.

Key findings will provide researcher information that drowning is a remarkably major issues in public health with associated in many preventable factors and existing awareness on drowning and drowning prevention, and recommendations for a substantial increase in comprehensive efforts and resources to reduce the unacceptably tragic outcome, especially among children and adolescents. 
Lack of awareness on a drowning risk among children is a significant problem that can be partly attributed to lack of knowledge and practice about the drowning prevention. In order to address these gaps, this study also aims to develop a health educational package on drowning prevention for parents and guardians of primary school children. Therefore, the data from the study will allow researcher to better understand the current status of childhood drowning prevention and to design drowning prevention strategies that are more likely to be successful.

\section{References}

Amar-Singh, H. S. S., Pui, S. T., \& Lina, H. (2011). Prevention of Childhood Drowning in Malaysia. 17, $1-18$.

Amar-Singh, H. S. S., Pui, S. T., \& Lina, H. (2014). Childhood drowning in Malaysia. International Journal of Injury Control and Safety Promotion, 21(1), 75-80.

https://doi.org/10.1080/17457300.2013.792284

Brenner, R. A. (2003). American academy of pediatrics. Pediatrics, 111(2), 426-435. https://doi.org/10.1542/peds.2005-1877

Brenner, R. A., Saluja, G., \& Smith, G. S. (2003). Swimming lessons, swimming ability, and the risk of drowning. Injury Control and Safety Promotion, 10(4), 211-216.

https://doi.org/10.1076/icsp.10.4.211.16775

Bugeja, L., Cassell, E., Brodie, L. R., \& Walter, S. J. (2014). Effectiveness of the 2005 compulsory personal flotation device (PFD) wearing regulations in reducing drowning deaths among recreational boaters in Victoria, Australia. Injury Prevention : Journal of the International Society for Child and Adolescent Injury Prevention, 20(6), 387-392.

Callaghan, J. A., Hyder, A. A., Khan, R., Blum, L. S., Arifeen, S., \& Baqui, A. H. (2010). Child supervision practices for drowning prevention in rural Bangladesh: A pilot study of supervision tools. Journal of Epidemiology and Community Health, 64, 645-647. https://doi.org/10.1136/jech.2008.080903

Cummings, P., Mueller, B. A., \& Quan, L. (2011). Association between wearing a personal floatation device and death by drowning among recreational boaters: A matched cohort analysis of United States Coast Guard data. Injury Prevention : Journal of the International Society for Child and Adolescent Injury Prevention, 17(3), 156-159.

Department of Statistics Malaysia (DOS). (2019). Department of Statistics Malaysia Press Release: Statistics on Causes of Death, Malaysia, 2019. In Department of Statistics Malaysia (Issue November).

Engel, S. C. (2015). Drowning episodes: prevention and resuscitation tips. Journal of family practice, 64(2), E1-E6.

Gulliver, P., \& Begg, D. (2005). Usual water-related behaviour and 'near-drowning'incidents in young adults. Australian and New Zealand journal of public health, 29(3), 238-243.

Harris, C. R., Jenkins, M., \& Glaser, D. (2006). Gender Differences in Risk Assessment : Why do Women Take Fewer Risks than Men ? Judgment and Decision Making, 1(1), 48-63.

Infographic Bernama \& Fire and Rescue Department. (2019). Statistic of areas with drowning cases in 2019.

International Life Saving Federation (ILSF). (2015). Drowning prevention strategies framework to reduce drowning deaths in the aquatic environment for nations / regions engaged in lifesaving (Issue July).

Laosee, O., Khiewyoo, J., \& Somrongthong, R. (2013). Drowning risk perceptions among rural 
INTERNATIONAL JOURNAL OF ACADEMIC RESEARCH IN BUSINESS AND SOCIAL SCIENCES

Vol. 11, No. 15, Empowering Youth and Community Wellbeing for Sustainable Development, 2021, E-ISSN: 2222-6990 @ 2020 HRMARS

Guardians: A community-based household survey. 2(1), 2-5.

https://doi.org/10.4172/scientificreports.5

Liu, Z., Kong, F., Yin, L., Wang, A., Xiong, L., Xie, D., Chen, L., \& Sheng, X. (2019). Epidemiological characteristics and influencing factors of fatal drowning in children under 5 years old in Hunan Province, China: Case-control study. BMC Public Health, 19(1), 1-8. https://doi.org/10.1186/s12889-019-7241-z

McCool, J., Ameratunga, S., Moran, K., \& Robinson, E. (2009). Taking a risk perception approach to improving beach swimming safety. International Journal of Behavioral Medicine, 16(4), 360-366. https://doi.org/10.1007/s12529-009-9042-8

McCool, J. P., Moran, K., Ameratunga, S., \& Robinson, E. (2008). New Zealand beachgoers' swimming behaviors, swimming abilities, and perception of drowning risk. International Journal of Aquatic Research and Education, 2, 7-15.

Moran, K. (2008). Re-thinking drowning risk: the role of water safety knowledge, attitudes and behaviours in the aquatic recreation of New Zealand youth: a thesis presented in fulfilment of the requirements for the degree of Doctor of Philosophy at Massey University, Palme.

Moran, K., Stanley, T., \& Rutherford, A. (2012a). Toddler drowning prevention: Teaching parents about child CPR in conjunction with their child's in-water lessons. International Journal of Aquatic Research and Education, 6(4), 315-324. https://doi.org/10.1080/17457300600678201

Moran, K., Stanley, T., \& Rutherford, A. (2012b). Toddler drowning prevention: Teaching parents about water safety in conjunction with their child's in-water lessons. International Journal of Aquatic Research and Education, 6(4), 315-324. https://doi.org/10.1080/17457300600678201

Moran, K., \& Willcox, S. (2013). Water safety practices and perceptions of "New" Zealanders. 136146.

Morrongiello, B. A., Sandomierski, M., Schwebel, D. C., \& Hagel, B. (2013). Are parents just treading water? the impact of participation in swim lessons on parents' judgments of children's drowning risk, swimming ability, and supervision needs. Accident Analysis and Prevention, 50, 1169-1175. https://doi.org/10.1016/j.aap.2012.09.008

Mulyono, S. (2010). Injury prevention. Public Health, 2 (November).

Peden, M., Oyegbite, K., Ozanne-Smith, J., Hyder, A. A., Branche, C., AKM, Fazlur Rahman Frederick, R., \& Bartolomeos, K. (2008). World report on child injury prevention. In Geneva, Switzerland. https://doi.org/10.1136/ip.2007.018143

Petrass, L. A., \& Blitvich, J. D. (2014). Preventing adolescent drowning: Understanding water safety knowledge, attitudes and swimming ability. The effect of a short water safety intervention. Accident Analysis and Prevention, 70, 188-194. https://doi.org/10.1016/j.aap.2014.04.006

Petrass, L. A., Blitvich, J. D., \& Finch, C. F. (2011). Lack of caregiver supervision: A contributing factor in Australian unintentional child drowning deaths, 2000-2009. Medical Journal of Australia, 194(5), 228-231. https://doi.org/pet10849_fm [pii]

Portal MyHEALTH. (2019). Drowning. Retrieved May 2, 2020, from http://www.myhealth.gov.my/en/drowning-2/

Rahman, A., Shafinaz, S., Linnan, M., \& Rahman, F. (2008). Community perception of childhood drowning and its prevention measures in rural Bangladesh: A qualitative study. The Australian Journal of Rural Health, 16(3), 176-180. https://doi.org/10.1111/j.1440-1584.2008.00969.x

Rahman, F., Bose, S., Linnan, M., Rahman, A., Mashreky, S., Haaland, B., \& Finkelstein, E. (2012). Costeffectiveness of an injury and drowning prevention program in Bangladesh. Pediatrics, 130, e1621-8. https://doi.org/10.1542/peds.2012-0757 
Schwebel, D. C., Lindsay, S., \& Simpson, J. (2007). Brief Report: A Brief Intervention to Improve Lifeguard Surveillance at a Public Swimming Pool. Journal of Pediatric Psychology, 32(7), 862868. https://doi.org/10.1093/jpepsy/jsm019

The Canadian Red Cross Society. (2003). What we have learned: 10 years of pertinent facts about drownings and other water-related injuries in Canada 1991-2000.

Thompson, D. C., \& Rivara, F. P. (2000). Pool fencing for preventing drowning in children. Cochrane Database of Systematic Reviews (Online), 2, CD001047. https://doi.org/10.1002/14651858.CD001047

Tyebally, A., \& Ang, S. Y. (2010). Kids can't float: Epidemiology of paediatric drowning and neardrowning in Singapore. Singapore Medical Journal, 51(5), 429-433.

World Health Organization (WHO). (2016). Global report on drowning: a leading killer. 58.

Yang, L., Nong, Q.-Q., Li, C.-L., Feng, Q.-M., \& Lo, S. K. (2007). Risk factors for childhood drowning in rural regions of a developing country: a case-control study. Injury Prevention : Journal of the International Society for Child and Adolescent Injury Prevention, 13(3), 178-182. https://doi.org/10.1136/ip.2006.013409 
INTERNATIONAL JOURNAL OF ACADEMIC RESEARCH IN BUSINESS AND SOCIAL SCIENCES

Vol. 11, No. 15, Empowering Youth and Community Wellbeing for Sustainable Development, 2021, E-ISSN: 2222-6990 @ 2020 HRMARS 